\title{
Chemical Colitis due to Peracetic Acid: a Case Report and Review of Literafure
}

\author{
Angelo Zullo, Cesare Hassan, Alessandra Guarini, Roberto Lorenzetti, Salvatore Campo, \\ Sergio Morini
}

Gastroenterology and Digestive Endoscopy, "Nuovo Regina Margherita" Hospital, Rome, Italy

\begin{abstract}
Reprocessing of both endoscopic instruments and reusable disposals is mandatory to prevent infection transmission. However, toxic colitis due to endoscope contamination by different disinfectants following an imperfect washing has been reported. We present a case of peracetic acid-induced colitis and reviewed the literature. Overall, five cases of peracetic acid toxic colitis have been reported. All cases presented with "snow white sign" immediately appearing during endoscopy, two patients complaint of mild abdominal pain (one of whom had also fever and rectal bleeding), whilst the othesr remained totally asymptomatic. Only one patient received a 1-week metronidazole treatment. No immediate complications were observed, and no sequels occurred at clinical-endoscopic follow-up. The identified cause of disinfectant contamination was a defective either manual or automated rinsing of the colonoscope following the reprocessing procedure.(J Dig Endosc 2011;2(1):15-17)
\end{abstract}

Keywords: Toxic colitis - Chemical colitis - Peracetic acid - induced colitis - Reprocessing - Colonoscopy

\section{Introduction}

Reprocessing of both endoscopic instruments and reusable disposals is mandatory to prevent the risk of infection transmission during an endoscopic procedure.[1] In digestive endoscopy, the reprocessing is generally performed by using dedicated machines, which utilize different chemical compounds. These disinfectants are fully removed during procedure by rinsing and drying the instruments. However, there is evidence that a chemical colitis may occur following an imperfect washing of endoscopes, due to a direct contact between the toxic disinfectant and colonic mucosa.[2-4] Glutaraldehyde is among the most widely used disinfectants in digestive endoscopy, and survey on 79 Italian Endoscopic Units found that such a compound was used for reprocessing by $67.1 \%$ of centres. [1] A recent systematic review described several cases of glutaraldehyde-induced toxic colitis, and an incidence of $0.1-4.7 \%$ is reported.[3] Although such a colitis may be selflimiting, some cases required a medical therapy and/or hospitalization due to toxic status.[3] In addition, glutaraldehyde is well known to be irritant for operators involved in the reprocessing following either inhalation or cutaneous exposure, causing ocular, nasal, and respiratory irritation as well as dermatitis.[5] Peracetic acid is second most used disinfectant for the reprocessing in Italy. [1] Such a compound is much less toxic as compared to glutaraldehyde for the operators who performed the reprocessing procedure. [6,7] and it is foreseeable that its use will increases in the future. However, peracetic acid-induced colitis is also possible, and we previously described two cases.[8] We report herein an additional case and performed a systematic review of the literature.

\section{Case report}

A 75-old-year woman with recurrent abdominal pain and slightly elevated values of carcinogen embrionic antigen

Reprints requests and correspondence:

Dott. Angelo Zullo, MD

Ospedale Nuovo Regina Margherita

Gastroenterologia ed Endoscopia Digestiva

Via E. Morosini, 30; 00153 Rome, Italy

Tel.: 00390658446608 Fax: 00390658446533

e-mail: zullo66@yahoo.it

Received: 10th March 2010 Accepted: 17th June 2010 
was referred by her physician for a total colonoscopy. Following a mild sedation, the procedure was performed without any difficulty until the caecum by using a standard colonoscope (Olympus CF-Q145). During the withdrawl phase, a sessile polyp measuring $5 \mathrm{~mm}$ in diameter was detected in the descending colon. Before performing the polypectomy, the region was washed with a small amount of water pushed with a sterilized syringe through the operative channel of the colonoscope. Immediately, some "snow white signs" appeared in the area of mucosa washed forming whitish plaque lesion sparing the polyp (Figure 1A). The patient remained asymptomatic, and the polypectomy was performed by using cold snare (Figure 1B). The technical control of the reprocessing machine performed in the same day of the chemical colitis event failed to find its malfunctioning. The patient remained totally asymptomatic without any abnormality of laboratory tests performed in the afternoon. One month later she underwent clinical ambulatory control without to complain symptoms.

\section{Review of literature}

Computer-assisted search was performed utilizing the PUBMED. The search was performed on all English, Italian, French and Spanish language articles through November 2009, using the exploded medical subject heading terms colitis, peracetic acid, reprocessing, colonoscopy. Boolean operators (NOT, AND, OR) were also used in succession to narrow and widen the search. Only those studies concerning such a disinfectant used during the endoscope reprocessing were considered. The full paper of all studies was retrieved, and manual searches of reference lists from identified relevant papers were performed to identify any additional studies that may have been missed using the above-mentioned procedure. From each study, data were extracted concerning (a) the main symptom at toxic colitis onset; (b) the most evident endoscopic finding; (c) the clinical follow-up; (d) the endoscopic follow-up; (e) possible complications; (f) the possible cause of contamination.

We identified five relevant studies. [4,8-11] However, the case series reported by Cammarota et al. was not taken into account since, following an automated reprocessing procedure with peracetic acid, endoscopes were also flushed with 3\% hydrogen peroxide solution, and toxic colitis was attributed to such a compound instead of peracetic acid.[4] Moreover, Lapeyre revealed to having observed several cases of toxic colitis which occurred in an epidemic pattern within few weeks when a semiautomated machine using peracetic acid was introduced for reprocessing, but no specific data on patients were provided.[11] Overall, three reports were available describing five cases of peracetic acid-induced colitis. [8-10] As reported in Table, all cases presented with "snow white sign" at endoscopy, two patients complained of mild abdominal pain (one of whom also had fever and rectal bleeding). No immediate complications were observed, and no sequels occurred at clinical-endoscopic follow-up. The identified cause of disinfectant contamination was a defective
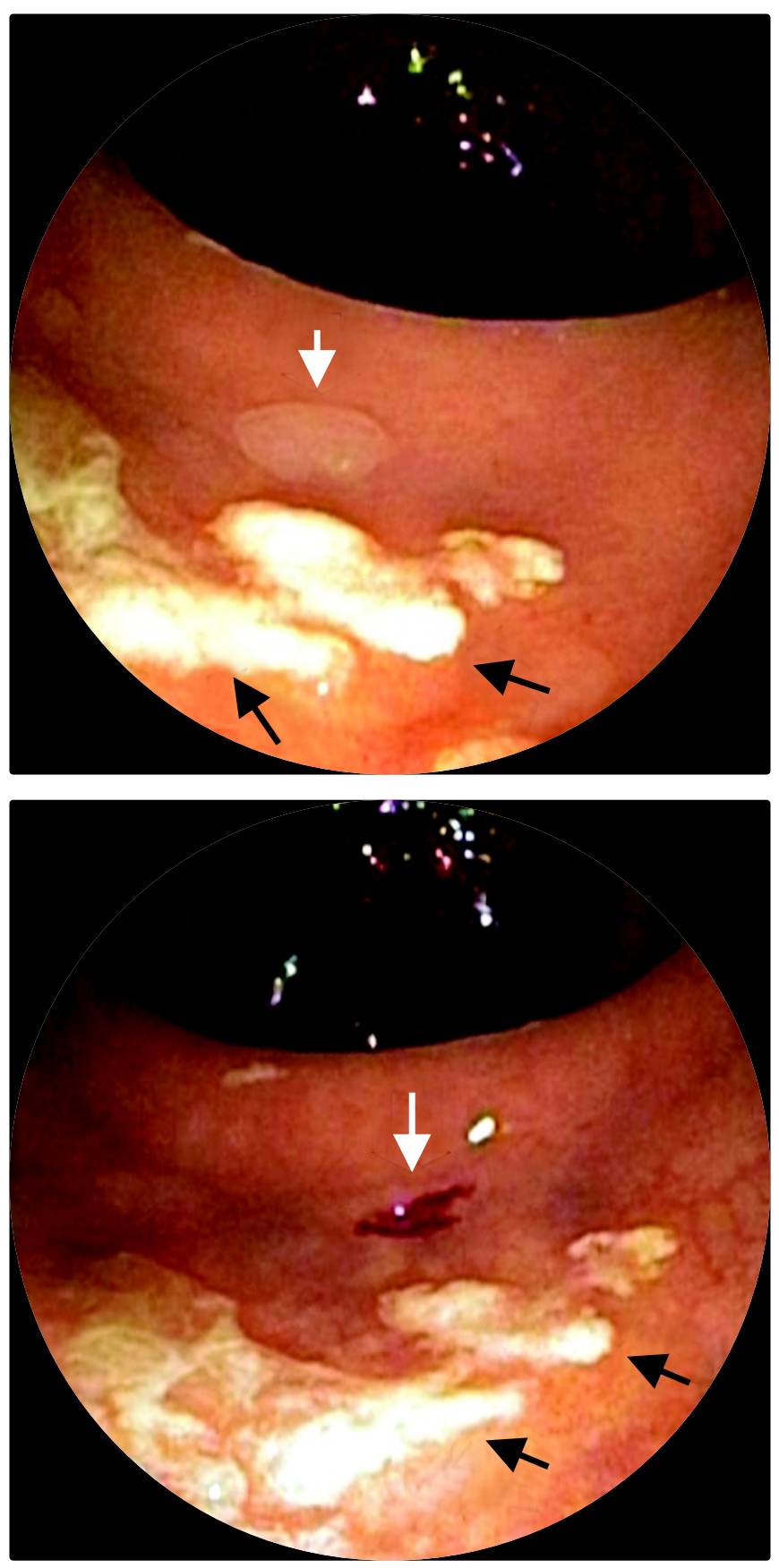

Figure 1(a): Snow white sign (black arrows) and sessile polyp (white arrow), (b) Snow white sign (black arrows) and polypectomy site (white arrow)

manual or automated rinsing of the colonoscope following the reprocessing procedure.

\section{Discussion}

Like to hydrogen peroxide, [4] the toxic damage of peracetic acid mainly depend on release of free oxygen and hydrogen radicals when in contact with colonic mucosa. Overall, five cases of toxic colitis surely induced by peracetic acid have been reported in the literature.[8-10] The present 
Table 1: Clinical features, endoscopic findings, treatment and follow-up of reported cases

\begin{tabular}{|c|c|c|c|c|c|c|}
\hline Author & $\begin{array}{l}\text { Endoscopic } \\
\text { feature }\end{array}$ & Symptoms & $\begin{array}{l}\text { Clinical } \\
\text { follow-up }\end{array}$ & $\begin{array}{l}\text { Endoscopic } \\
\text { follow-up }\end{array}$ & Therapy & $\begin{array}{l}\text { Cause of } \\
\text { contamination }\end{array}$ \\
\hline Coton (9) & $\begin{array}{l}\text { Snow white } \\
\text { Sign }\end{array}$ & $\begin{array}{l}\text { Abdominal pain, } \\
\text { recta; bleeding and } \\
\text { fever }>6 \text { hours }\end{array}$ & $\begin{array}{l}1 \text { week; } \\
\text { asymptomatic }\end{array}$ & $\begin{array}{l}3 \text { weeks: } \\
\text { normal mucosa }\end{array}$ & $\begin{array}{l}\text { Metronidazole } \\
\text { for } 7 \text { days }\end{array}$ & $\begin{array}{l}\text { Defective manual } \\
\text { rinsing of a } \\
\text { colonoscope channel }\end{array}$ \\
\hline Coriat (10) & $\begin{array}{l}\text { Snow white } \\
\text { sign }\end{array}$ & $\begin{array}{l}\text { Mild abdominal pain } \\
\text { self-limiting within } \\
48 \text { hours }\end{array}$ & $\begin{array}{l}2 \text { weeks } \\
\text { asymptomatic }\end{array}$ & $\begin{array}{l}2 \text { weeks: } \\
\text { normal mucosa }\end{array}$ & None & $\begin{array}{l}\text { Defective manual } \\
\text { rinsing of a } \\
\text { colonoscope channel }\end{array}$ \\
\hline Morini (8) & $\begin{array}{l}\text { Snow white } \\
\text { sign }\end{array}$ & None & $\begin{array}{l}2 \text { months: } \\
\text { asymptomatic }\end{array}$ & $\begin{array}{l}2 \text { months: } \\
\text { normal mucosa }\end{array}$ & None & $\begin{array}{l}\text { Defective automated } \\
\text { rinsing of adjunctive } \\
\text { channel for washing }\end{array}$ \\
\hline Morini (8) & $\begin{array}{l}\text { Snow white } \\
\text { sign }\end{array}$ & None & $\begin{array}{l}6 \text { months: } \\
\text { asymptomatic }\end{array}$ & $\begin{array}{l}6 \text { months: } \\
\text { normal mucosa }\end{array}$ & None & $\begin{array}{l}\text { Defective automated } \\
\text { rinsing of adjunctive } \\
\text { channel for washing }\end{array}$ \\
\hline Present report & $\begin{array}{l}\text { Snow white } \\
\text { sign }\end{array}$ & None & $\begin{array}{l}4 \text { weeks: } \\
\text { asymptomatic }\end{array}$ & Not done & None & $\begin{array}{l}\text { Defective automated } \\
\text { rinsing of operative } \\
\text { channel }\end{array}$ \\
\hline
\end{tabular}

review showed that such a damage invariably presents with "snow white signs" at endoscopic observation, the clinical feature is generally mild and self-limiting, probably not requiring neither hospitalization nor therapy. These observations would suggest that peracetic acid-induced colitis seems to be less severe than glutaraldehyde-induced colitis, for which medical therapy and/or hospitalization due to severe colitis or toxic status have been occasionally required.[3] This could depend on the more superficial effect of peracetic acid on colonic mucosa as compared to glutaraldehyde. Indeed, at histological assessment, peracetic acid-induced colitis is characterized by empty spaces between $\mathrm{m}$

ucosal glands which are largely spared from the toxic damage.[4] whilst glutaraldehyde acts more deeply injuring the glandular crypts.[12]

Reprocessing of instrument is mandatory following each endoscopic procedure to prevent infection transmission. Several cases of toxic colitis due to different chemical compounds, including glutaraldehyde and hydrogen peroxide, have been described.[3,4] The present review suggest that peracetic acid-induced colitis is also possible. All cases occurred following an either manual or automated defective reprocessing procedure, mainly due to an imperfect rinsing of operative channels of colonoscope. Therefore, following a manual procedure, an accurate rinsing and drying is mandatory to minimize patients' exposure to residual disinfecting chemicals in the endoscope.[13] When an automatic disinfecting machine is employed, a strict adherence to proper maintenance and volume adjustments in the rinse cycle is mandatory.[12]

\section{References}

1. Spinzi G, Fasoli R, Centenaro R, Minoli G, SIED Lombardia
Working Group. Reprocessing in digestive endoscopy units in Lombardy: results of a regional survey. Dig Liver Dis 2008;40:890-6.

2. Sheibani S, Gerson LB. Chemical colitis. J Clin Gastroenterol 2008;42:115-21.

3. Ahishali E, Uygur-Bayramic O, Dolapcioglu C, Dabak R, Mengi A, $\mathrm{I}^{\mathrm{o}} \mathrm{ik} \mathrm{A}, \mathrm{Ermi}^{\mathrm{O}} \mathrm{E}$. Chemical colitis due to glutaraldehyde: case series and review of the literature. Dig Dis Sci 2008 Dec 23 [Epud ahead of print].

4. Cammarota G, Cesaro P, Cazzato A, Fedeli P, Riccioni ME, Sparano $\mathrm{L}$, Vitale $\mathrm{G}$ et al. Hydrogen peroxide-related colitis (previously known as "pseudolipomatosi"): a series of cases occurring in an epidemic pattern. Endoscopy 2007;39: 916-9.

5. Ballantyne B, Jordan SL. Toxicological, medical and industrial hygiene aspects of glutaraldehyde with particular reference to its biocidal use in cold sterilization procedures. J Appl Toxicol 2001; 21:131-51.

6. Rideout K, Teschke K, Dimich-Ward H, Kennedy SM. Considering risks to healthcare workers from glutaraldehyde alternatives in highlevel disinfection. J Hosp Infect 2005;59:4-11.

7. Pacenti M, Dugheri S, Boccalon P, Arcangeli G, Cupelli V. Evaluation of occupational exposure to high-level disinfectants in endoscopic services in an Italian hospital. Int J Immunopathol Pharmacol 2006;19 (Suppl. 4):73-7.

8. Morini S, Campo SMA, Zullo A, Guarini A, Ridola L, Hassan C. Chemical colitis induced by peracetic acid: further evidence. Endoscopy 2009; 41:383 (letter).

9. Coton T, Bohand X, Guisset M, Carre D, Delpy R, Valette M, Debonne JM. Colite aigue induite par une solution de désinfenction des endoscopes à base d'acide peracétique (acute colitis induced by a peracetic acid solution used to disinfect endoscopes). Gastroenterol Clin Biol 2003;27:556-58.

10. Coriat R, Chaput U, Ismaili Z, Chaussade S. What induces colitis? Hydrogen peroxide or peracetic acid? Endoscopy 2007;40:231 (letter).

11. Lapeyre B. The "frost sign" and the "snow white sign": intramucosal air injection or peroxide colitis? Endoscopy 2005;37:679 (letter).

12. Ryan CK, Potter GD. Disinfectant colitis. Rinse as well as you wash.J Clin Gastroenterol 1995;21:6-9.

13. Martiny $\mathrm{H}$, Floss $\mathrm{H}$. Residuals on medical devices following reprocessing.J Hosp Infect 2001;48 (Suppl A):S88-92. Review

Source of support: Nil; Conflict of interest: none declared 